\title{
ANÁLISE DO PROCESSO DE LIXIVIAÇÃO DAS CINZAS DE CALDEIRAS DE RECUPERAÇÃO QUÍMICA
}

\author{
T. M. FREITAS, P.S.S PORTO, T. S. de LIRA e M. S. BACELOS \\ Universidade Federal do Espírito Santo, Centro Universitário Norte do Espírito Santo, Programa \\ de Pós-graduação em Energia, Departamento de Engenharias e Tecnologia \\ E-mail para contato: marcelo.bacelos@ufes.br
}

\begin{abstract}
RESUMO - Na indústria, o acúmulo de substâncias (cloreto e o potássio) não processáveis no ciclo de recuperação de produtos químicos na caldeira pode causar corrosão e incrustação nos equipamentos. A lixiviação das cinzas da caldeira de recuperação química é uma técnica viável que promove a remoção seletiva destes componentes. Dessa maneira, o objetivo deste trabalho é analisar o processo de lixiviação de cinzas, verificando o efeito das variáveis de processo (temperatura, massa específica da lama e pH) sobre o grau de separação das fases, mediante ensaios de decantação. A análise dos dados indicou que as variáveis de processo que afetam significativamente a separação das fases são a massa específica e o $\mathrm{pH}$. Os valores ótimos que maximizam a variável resposta foram de $1,35 \mathrm{~g} / \mathrm{mL}$ para passa específica e 8,5 para o $\mathrm{pH}$.
\end{abstract}

\section{INTRODUÇÃO}

As indústrias brasileiras de papel e celulose ocupam uma posição de destaque no atual cenário mundial. Segundo dados da Associação Brasileira de Celulose e Papel (BRACELPA), em 2011, o Brasil foi o quarto maior produtor mundial de celulose. Já o boletim mensal divulgado pela Bracelpa, em Janeiro de 2014, mostra um aumento, de aproximadamente $75 \%$, na produção brasileira de celulose, no período de 2002 a 2012. Isso se deve à crescente demanda de celulose, cada vez mais orientada para o mercado externo.

Diante da alta competitividade gerada pela grande demanda do produto em questão, tornase imprescindível que as indústrias desse setor centralizem seus esforços no sentido de redução nos custos dos processos envolvidos. Desta maneira, estudos envolvendo a otimização do processo cíclico de recuperação dos produtos químicos utilizados na produção da polpa de celulose contribuem para que a indústria atinja suas metas. Entretanto, este recurso provoca o acúmulo de substâncias indesejáveis ao processo - os elementos não processáveis (NPEs). Tais substâncias reduzem a eficiência dos equipamentos pela formação de depósitos e incrustações ou pelo processo de corrosão (EMUNDS et al., 2006).

Desta forma, no ciclo de recuperação dos produtos químicos, é grande a preocupação com o aumento do conteúdo de NPEs, como cloreto e potássio, já que são os principais causadores desses problemas (HAMAGUCHI E VAKKILAINEN, 2010). Com o objetivo de reduzir a concentração de NPEs no ciclo, algumas técnicas estão sendo estudadas e utilizadas pelas 
empresas.

O diagrama de blocos genérico do processo de produção de celulose é apresentado na Figura 1.

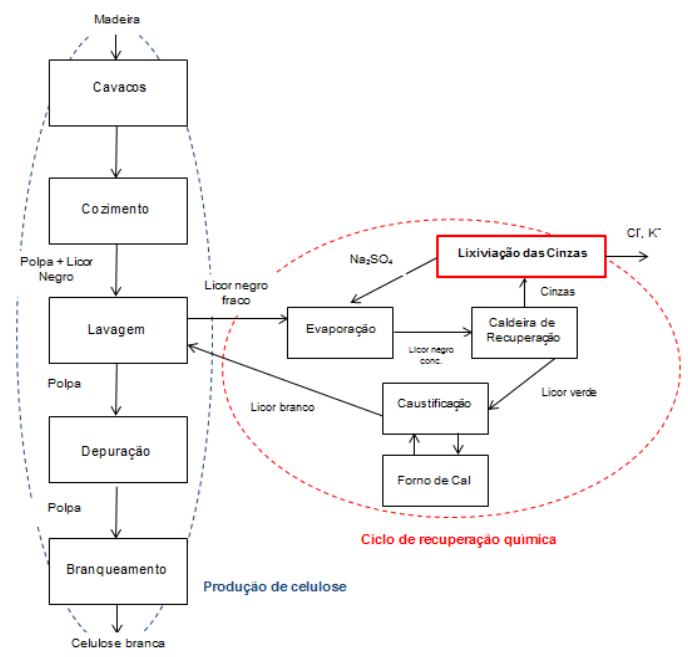

Figura 1 - Processo de fabricação de celulose e ciclo de recuperação química.

A Figura 1 também evidencia o ciclo de recuperação dos produtos químicos utilizados na produção da polpa. Esse subsistema, que é de suma importância para a indústria, está circulado em vermelho. O processo de lixiviação das cinzas é a técnica de remoção de NPEs que será abordada neste trabalho, e está em destaque no ciclo. Essa técnica consiste na remoção seletiva dos compostos inertes presentes nas cinzas provenientes da caldeira de recuperação, sendo uma etapa complementar ao processo de recuperação de produtos químicos.

Para que o processo de lixiviação ocorra, cinzas e água são alimentadas em um tanque de lixiviamento formando uma lama que é constituída de duas fases. A fase líquida é enriquecida em cloreto e potássio, e a fase sólida é constituída principalmente de sulfato de sódio. Isso porque devido ao alto teor de sulfato na composição das cinzas forma-se uma solução supersaturada do mesmo. Para que a separação seja mais eficiente, a lama é bombeada para uma centrífuga que efetuará a separação pela diferença de densidade entre as fases. A fase sólida é direcionada novamente ao ciclo de recuperação e a parte líquida é descartada parcialmente. O esquema do processo de lixiviação das cinzas pode ser resumido como na Figura 2 seguinte.

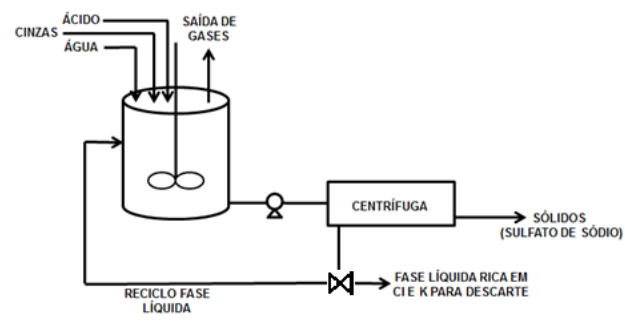

Figura 2 - Processo de lixiviação das cinzas. 


\section{OBJETIVO}

Este trabalho tem como objetivo analisar quais variáveis afetam o processo de lixiviação de cinzas da caldeira de recuperação química de uma indústria de papel e celulose. Para isso, um planejamento de experimentos é realizado de maneira a investigar o efeito de variáveis de processo sobre o grau de separação das fases presentes na lama. As variáveis investigadas são: massa específica e $\mathrm{pH}$. Ao final, também é proposto um modelo que permite descrever o processo, e, pela sua otimização, as condições ótimas para o mesmo são fixadas.

\section{METODOLOGIA EXPERIMENTAL}

A metodologia experimental é dividida em algumas etapas para possibilitar a realização da análise do efeito das variáveis de processo sobre o sistema em questão.

\subsection{Variável Resposta}

A variável resposta selecionada é o grau de separação entre as fases. Está é definida como a razão entre a altura da fase líquida sobrenadante e a altura total de ambas as fases e pode ser calculada- como:

$$
G S=\frac{h_{\text {fase }} \text { Iiquida }}{h_{\text {total }}} \times 100
$$

em que GS é o grau de separação, em \%, e as alturas, da fase líquida ( $\mathrm{h}_{\text {fase líquida }}$ e total ( $\left.\mathrm{h}_{\text {total }}\right)$, são em centímetros.

Se o grau de separação for de $0 \%$ não haverá distinção entre as fases, e consequentemente a remoção de cloreto e potássio será nula. À medida que o grau de separação aumenta, maior será a remoção desses compostos. O emprego desta variável resposta é desejável, pois, a eficiência do processo de lixiviação das cinzas pode estar relacionada com o grau de separação das fases presentes na lama.

\subsection{Variáveis Investigados}

As variáveis selecionadas são massa específica e pH da lama. Estas podem estar relacionados com a formação das fases e serão estudadas sob três níveis.

Os níveis de massa específica são selecionados de acordo com a consistência da lama. Para que a decantação ocorra, a lama deve estar em suspensão aquosa. Dados de processo sugerem os valores de $1,35 \mathrm{~g} / \mathrm{mL}, 1,43 \mathrm{~g} / \mathrm{mL}$ e $1,50 \mathrm{~g} / \mathrm{mL}$ como sendo satisfatório por obedecer a esta condição. A determinação dos níveis de $\mathrm{pH}$ é feita visando associar o grau de separação da lama frente a alterações na composição da cinza. Os valores de $\mathrm{pH}$ de 8,5, 9,75 e 11,0 são adequados visto que o $\mathrm{pH}$ de operação deve ser alcalino para que não haja a formação de produtos tóxicos. A Tabela 1 a seguir resume os níveis investigados das variáveis selecionadas. 
Tabela 1 - Níveis das variáveis selecionadas

\begin{tabular}{cccc}
\hline Variável & Nível Inferior & Nível Médio & Nível Superior \\
\hline Massa específica (g/mL) & 1,35 & 1,42 & 1,50 \\
pH & 8,50 & 9,75 & 11,0 \\
\hline
\end{tabular}

\subsection{Planejamento de Experimentos}

Com base na escolha das variáveis, em três níveis, o planejamento experimental utilizado é o $3^{2}$, resultando então em 9 experimentos, que combinam todos os fatores em todos os níveis.

\subsection{Procedimento Experimental}

Os ensaios de decantação são realizados em béqueres aleatoriamente. Primeiramente, é adicionado ao béquer a cinza juntamente com a água. A massa específica da lama resultante da mistura pode variar dependendo da proporção de cada componente. Assim, calcula-se a densidade pela massa da solução e o volume que a mesma ocupa em uma proveta. Na sequência, o pH da lama é ajustado para o valor de interesse pela adição de ácido sulfúrico. A medida que o ácido é adicionado o $\mathrm{pH}$ resultante é medido utilizando um $\mathrm{pH}$-metro. Por fim, para a manutenção da temperatura aproximada de $75^{\circ} \mathrm{C}$, a decantação é realizada sobre chapas de aquecimento. A duração de cada ensaio é de 1 hora. Após decorrido o tempo, é medido, com uma régua, a altura da fase líquida sobrenadante, e a altura total de ambas as fases. Uma razão entre esses valores, indica satisfatoriamente o grau de separação das fases. A Figura 3 ilustra algumas etapas deste procedimento.
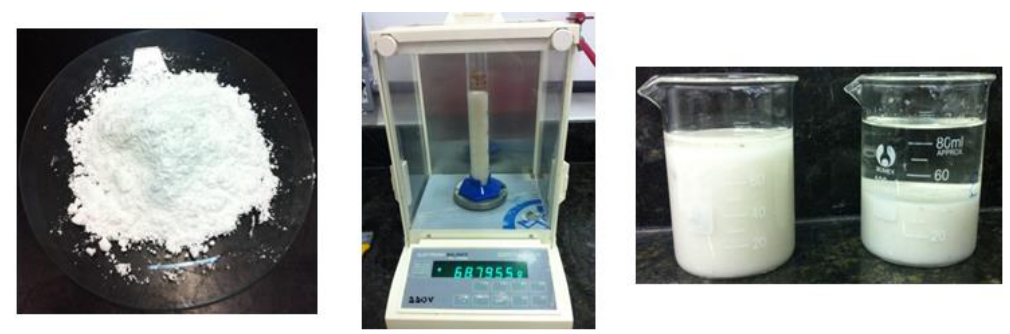

Figura 3 - Etapas do procedimento experimental.

\section{ANÁLISE DOS RESULTADOS}

\subsection{Dados Coletados}

Com a realização do procedimento experimental para coleta dos dados, os valores da variável resposta, para cada ensaio de decantação, foram obtidos e estão dispostos na Tabela 2.

Tabela 2 - Matriz de planejamento com a variável resposta coletada

\begin{tabular}{cccc}
\hline & Massa específica $(\mathbf{g} / \mathbf{m L})$ & $\mathbf{p H}$ & Grau de Separação $(\%)$ \\
\hline $\mathbf{5}$ & 1,425 & 9,75 & 63,63 \\
$\mathbf{6}$ & 1,425 & 11,0 & 10,71 \\
$\mathbf{8}$ & 1,500 & 9,75 & 37,50 \\
\hline
\end{tabular}


Tabela 2- continuação

\begin{tabular}{llll}
\hline $\mathbf{9}$ & 1,500 & 11,0 & 0,00 \\
$\mathbf{7}$ & 1,500 & 8,50 & 31,37 \\
$\mathbf{2}$ & 1,350 & 9,75 & 72,72 \\
$\mathbf{1}$ & 1,350 & 8,50 & 85,71 \\
$\mathbf{4}$ & 1,425 & 8,50 & 62,96 \\
$\mathbf{3}$ & 1,350 & 11,0 & 52,00 \\
\hline
\end{tabular}

\subsection{Análise Estatística}

Para a realização dos cálculos matemáticos das hipóteses estatísticas foi utilizado um software convencional que também permite a apresentação dos métodos estatísticos no formato de tabelas e gráficos. A Tabela 3 mostra a análise de variância para o experimento realizado.

Tabela 3 - Análise de variância

\begin{tabular}{cccccc}
\hline & $\begin{array}{c}\text { Soma } \\
\text { Quadrática }\end{array}$ & $\begin{array}{c}\text { Graus de } \\
\text { Liberdade }\end{array}$ & $\begin{array}{c}\text { Média } \\
\text { Quadrática }\end{array}$ & F-Fisher & p-valor \\
\hline (1)Massa específica(L) & 3339,872 & 1 & 3339,872 & 30,9776 & 0,0114 \\
Massa específica(Q) & 1,227 & 1 & 1,227 & 0,0114 & 0,9218 \\
$(\mathbf{2}) \mathbf{p H}(\mathbf{L})$ & 2294,388 & 1 & 2294,388 & 21,2806 & 0,0192 \\
$\mathbf{p H}(\mathbf{Q})$ & 611,917 & 1 & 611,917 & 5,6756 & 0,0974 \\
1L e 2L & 1,369 & 1 & 1,369 & 0,0127 & 0,9174 \\
Erro & 323,448 & 3 & 107,816 & & \\
Total & 6572,221 & 8 & & & \\
\hline
\end{tabular}

Como se pode observar, o componente quadrático puro da massa específica não afeta a variável resposta visto que o p-valor para esse parâmetro é maior que o nível de significância adotado de 0,05. A mesma análise é feita para a interação linear entre massa específica e pH. Assim esses parâmetros não influenciam a variável resposta, e por isso podem ser ignorados e não são incorporados ao modelo.

Para se determinar um modelo matemático para o processo em questão é necessário conhecer o efeito que cada fator possui sobre a variável resposta. Isso é calculado mensurando a alteração ocorrida na variável resposta a partir das mudanças de nível nos fatores. A Tabela 4 a seguir resume esses efeitos. 
Tabela 4 - Estimativa dos efeitos

\begin{tabular}{ccccccc}
\hline & Efeito & $\begin{array}{c}\text { Desvio } \\
\text { padrão }\end{array}$ & t(5) & p-valor & $\begin{array}{c}\mathbf{- 9 5 . \%}- \\
\text { Intervalo } \\
\text { Confiança }\end{array}$ & $\begin{array}{c}\mathbf{+ 9 5 . \%}- \\
\text { Intervalo } \\
\text { Confiança }\end{array}$ \\
\hline Média & 46,2889 & 2,6917 & 17,1967 & $<0,0001$ & 39,3696 & 53,2082 \\
$\begin{array}{c}\text { (1)Massa } \\
\text { específica (L) }\end{array}$ & $-47,1867$ & 6,5934 & $-7,1567$ & 0,0008 & $-64,1355$ & $-30,2379$ \\
$(\mathbf{2}) \mathbf{p H}(\mathbf{L})$ & $-39,1100$ & 6,5934 & $-5,9317$ & 0,0019 & $-56,0588$ & $-22,1612$ \\
$\mathbf{p H}(\mathbf{Q})$ & 17,4917 & 5,7100 & 3,0633 & 0,0280 & 2,8136 & 32,1697 \\
\hline
\end{tabular}

Neste caso, nota-se, na Tabela 4, que o termo quadrático do $\mathrm{pH}$ é considerado importante e por isso deve ser representado no modelo (o p-valor para esse parâmetro é menor que o nível de significância de 0,05 adotado). $\mathrm{O}$ mesmo pode ser afirmado para os componentes linear da massa específica e do $\mathrm{pH}$.

Efetuando a substituição dos parâmetros de efeito de acordo com a Tabela 4, e seguindo o modelo quadrático proposto por Calado e Montgomery (2003), o seguinte modelo é gerado para o experimento em questão.

$$
\mathrm{GS}=46,2889-23,5933 \mathrm{x}-19,5550 \mathrm{y}+8,7458 \mathrm{y}^{2}
$$

em que GS é o grau de separação das fases em \%, x a massa específica e y é o pH, com relação às variáveis codificadas.

A partir dessa equação, aproximações para o grau de separação das fases são obtidas, sem que o experimento seja realizado, entretanto, os valores de massa específica e $\mathrm{pH}$ selecionados devem estar compreendidos na faixa de realização do experimento.

Com a otimização do modelo feita no Matlab, os valores de massa específica e pH que maximizam o grau de separação das fases presentes na lama foram encontrados e os resultados estão dispostos na Tabela 5 a seguir.

Tabela 5 - Condições ótimas dos parâmetros

\begin{tabular}{cc}
\hline Parâmetro & Condição ótima \\
\hline Massa específica $(\mathbf{g} / \mathbf{m L})$ & 1,35 \\
$\mathbf{p H}$ & 8,5 \\
\hline
\end{tabular}

A análise de variância supõe que os erros do modelo são independentes e normalmente distribuídos com a mesma variância em cada nível do fator. Sendo assim, para que a análise estatística efetuada seja válida, esses pressupostos devem ser verificados pela análise de resíduos.

Primeiramente, a normalidade dos resíduos pode ser constatada pela probabilidade normal. Como pode ser observado na Figura 5, os pontos se aproximam dos valores normal esperados, indicando que os resíduos obedecem à distribuição normal. A fim de averiguar a independência e variância constante dos resíduos, a Figura 6 que representa os resíduos em função dos valores 
preditos pode ser utilizada. A análise dos dados na Figura 6, demonstra que nenhuma tendência é seguida, pois os dados apresentam um comportamento aleatórios em torno da reta imaginária correspondente ao resíduo nulo.

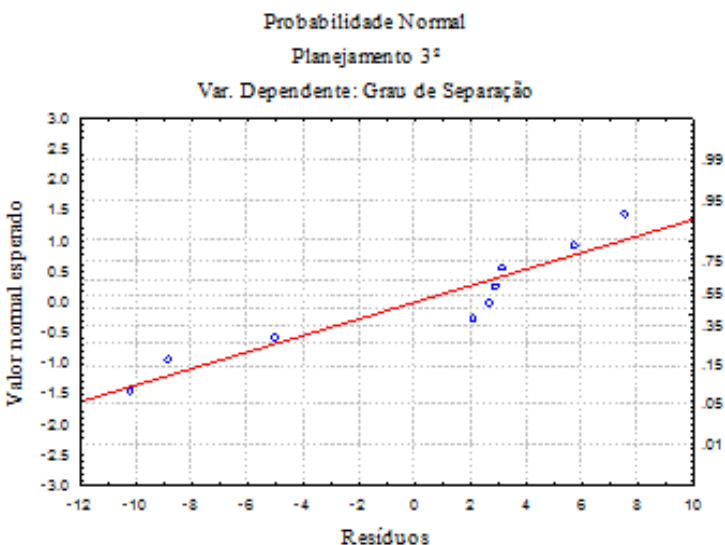

Figura 5 - Probabilidade normal

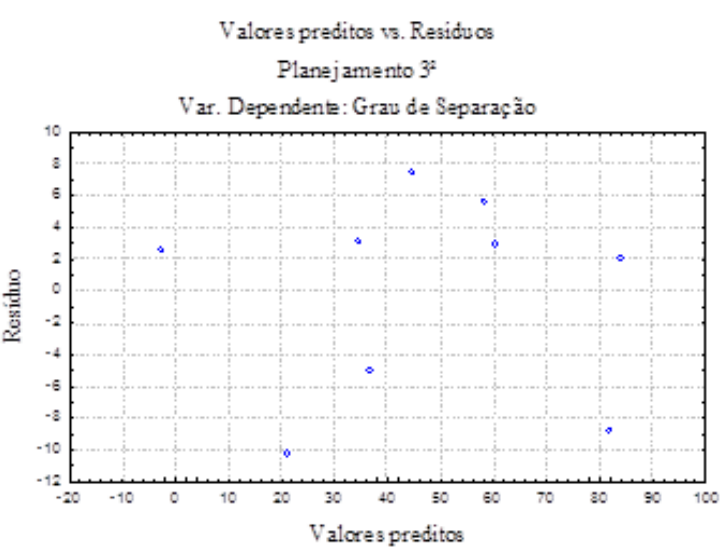

Figura 6- Valores preditos vs. resíduos

\subsection{Análise Técnica dos Dados}

A análise estatística dos ensaios de decantação permitiu observar o comportamento do processo frente aos diferentes parâmetros analisados. A partir dessa análise, algumas conclusões podem ser estabelecidas de modo a auxiliar a operação do processo de lixiviação das cinzas.

Primeiramente, é necessário assimilar o fato de que quanto maior a separação das fases, maior será a fase líquida sobrenadante que é uma solução saturada de sulfato de sódio, cloreto de sódio e potássio. Assim, quanto maior o grau de separação, mais cloreto e potássio serão removidos, o que é de interesse. Porém, o mesmo ocorre com o sulfato, o que não é desejável. Diante disso, os responsáveis pelo processo devem selecionar os parâmetros de acordo com suas necessidades e principalmente, de acordo com as restrições do processo.

Se for necessário tratar uma grande quantidade de cinzas, com o intuito de recuperar ao máximo o sulfato de sódio, o $\mathrm{pH}$ para o processo deve ser abaixado, pois, caso contrário, não haverá separação das fases na centrífuga. Assim, o processo será ineficiente. Outro fato a se destacar é que, se em determinado momento, tornar-se necessário reduzir os teores de cloreto e potássio na caldeira de recuperação sem se preocupar com o descarte de sulfato de sódio - isso pode ocorrer caso as taxas de corrosão e incrustação nas tubulações da caldeira estejam elevadas é indicado ajustar os parâmetros do processo para massa específica e $\mathrm{pH}$ de modo a maximizar o grau de separação das fases, ou seja, nos pontos ótimos, descritos na Tabela 5.

\section{CONSIDERAÇÕES FINAIS}

O fechamento do circuito de recuperação de produtos químicos utilizados na produção de celulose promove o acúmulo de elementos não processáveis na planta de recuperação. A 
lixiviação das cinzas se mostrou uma técnica atraente que visa a remoção desses compostos. A análise desse sistema por planejamento de experimentos é satisfatória por permitir a investigação e quantificação do comportamento do processo frente a alterações de variáveis a que ele está sujeito.

A densidade e o pH interferem significativamente no grau de separação das fases. Pela otimização do modelo gerado na análise estatística, as condições ótimas de operação foram determinadas, quando se deseja maximizar o grau de separação das fases. Os valores foram de $1,35 \mathrm{~g} / \mathrm{mL}$ para massa específica e de 8,5 para o $\mathrm{pH}$.

\section{REFERÊNCIAS}

BRACELPA - Associação Brasileira de Celulose e Papel. Panorama do Setor. Disponível em: <http://www.bracelpa.org.br/bra2/?q=node/34>. Acesso em 13 ago. 2013.

CALADO, V.; MOTGOMERY, D. C. Planejamento de Experimentos usando o Statistica. Rio de Janeiro, 2003.

CONJUNTURA BRACELPA. Disponível em: <http://www.bracelpa.org.br/bra2/?q=node/188> . Acesso em 05 fev. 2014.

EMUNDS, R. L.; CARDOSO, M.; MENDES, M. D. Elementos não processáveis na unidade de recuperação química da produção de celulose Kraft. O pap. 2006.

HAMAGUCHI, M.; VAKKILAINEN, E. Corrosão em tubos de superaquecedor de caldeiras de recuperação: um desafio. O pap., v 71, nº 6, p.57-71, 2010. 